Miami Nature Biotechnology Short Reports

TheScientificWorld (2001) 1 (S3), 53SR

ISSN 1532-2246; DOI 10.1100/tsw.2001.192

\title{
TRANSFERRIN ENSURES SURVIVAL OF OVARIAN CARCINOMA CELLS SUBJECTED TO DEFEROXAMINE, TNFA, FASL, TRAIL OR MYC-ACTIVATION
}

\author{
Sandra Fassl ${ }^{1}$, Georg Rosenberger ${ }^{1}$, Michael Grusch ${ }^{1}$, Gerhard Fuhrmann ${ }^{1}$, Katharina \\ Leuhuber $^{1,2}$, Doris Polgar ${ }^{1}$, and Georg Krupitza ${ }^{1 *}$ \\ ${ }^{1}$ Institute of Clinical Pathology; ${ }^{2}$ Institute of Zoology; University of Vienna, A-1090 Vienna, \\ Austria \\ *g.krupitza@akh-wien.ac.at
}

INTRODUCTION. Human ovarian adenocarcinoma N.1 cells apoptose upon Myc-activation when serum factors are limited (1). The downstream mechanism that is triggered by Myc is unknown, however. We discovered that Myc-activation and treatment with TNFa, FasL and TRAIL induces H-ferritin expression. H-ferritin is an intracellular iron chelator. Since also the pharmacological iron chelator deferoxamine induces apoptosis in N.1 cells, we investigated the regulation and the role of $\mathrm{H}$-ferritin in response to $M y c$-activation and TNFa treatment under serum free, pro-apoptotic conditions, and identified transferrin as a survival factor in N.1 human ovarian carcinoma cells.

METHODS. Western blotting, northern blotting and DNA fragmentation and apoptosis assays were performed according to standard procedures and transfection and retroviral transduction according to standard protocols.

RESULTS. When N.1 cells are treated with TRAIL, FasL or TNFa under serum deprived cell culture conditions, which is a prerequisite to induce apoptosis, H-ferritin becomes upregulated (Fig. 1a). Under non-apoptotic conditions, i.e. when cells are maintained under $10 \%$ fetal calf serum, the treatment with these inducers prevents cell death (2) and also H-ferritin levels are not induced (Fig. 1b). Activation of an ectopic Myc:ER construct also induces H-ferritin expression when serum is withdrawn, not however in presence of serum. Therefore we assumed that intracellular iron sequestration might be a trigger mechanism of Myc-induced apoptosis. Hence, transferrin was substituted for serum and this, in fact, rescues from apoptosis and does not allow for $\mathrm{H}$-ferritin induction (Fig. 1c). Substitution of transferrin for serum also aborts cell death elicited by TNFa, FasL and TRAIL (Fig. 2), and moreover, prevents downregulation of Akt during TNFa-treatment. 

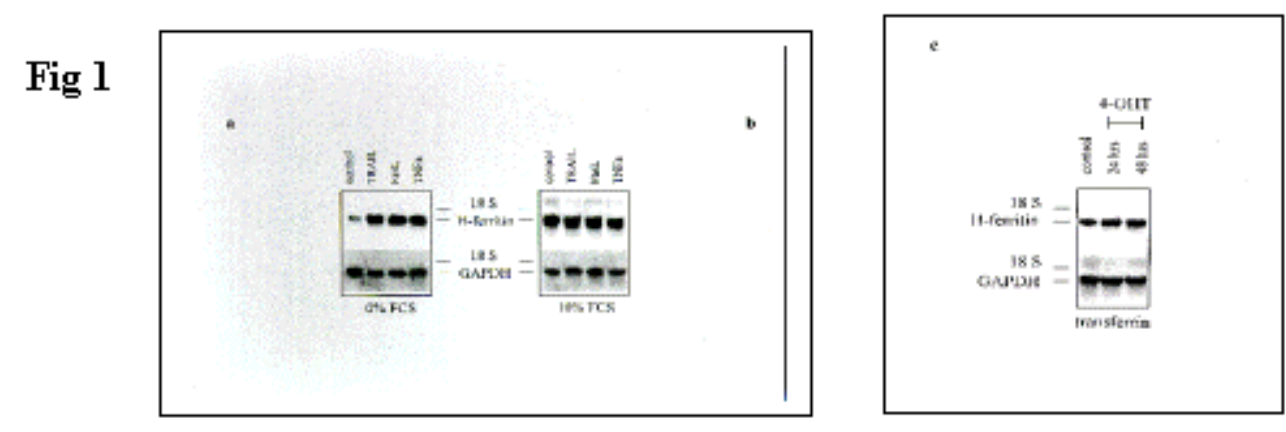

\section{Fig 2}

\begin{tabular}{|c|}
\hline 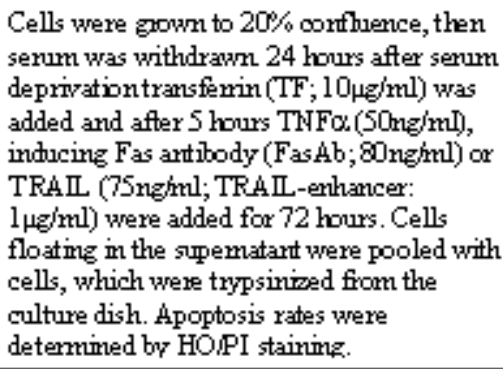 \\
\hline
\end{tabular}

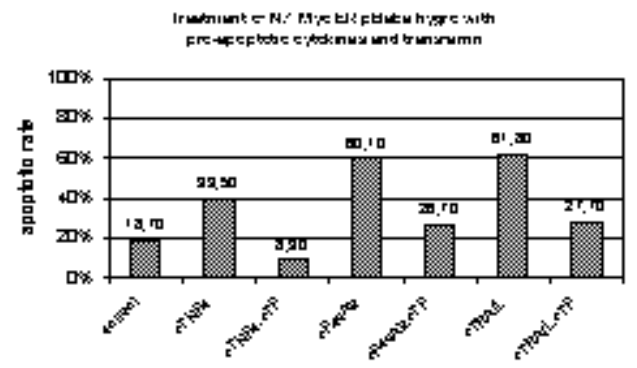

CONCLUSION. These data suggest that Myc-activation, FasL, TNFa and TRAIL disturb cellular iron homeostasis and that this is an apoptotic trigger. TNFa suppresses constitutive levels of Akt and phosphorylated Akt, which are restored in presence of transferrin. Downregulation of Akt might generate an apoptosis-prone state in N.1 cells by inhibiting a major survival pathway.

It was shown recently that H-ferritin is a target of c-Myc which downregulates its expression under high serum conditions and thereby induces proliferation (3). It can be speculated whether the distinct regulation of $\mathrm{H}$-ferritin by Myc is a switch for the dual pathway that either promotes Myc-triggered growth or apoptosis, depending on survival factor availability.

ACKNOWLEDGEMENT. This work was supported by the Austrian National Bank Fond No.: 7220, the Herzfelder'sche family foundation, and the Anton Dreher memory foundation.

\section{REFERENCES.}

1. Fuhrmann, G., Rosenberger, G., Grusch, M., Klein, N., Hofmann, J., and Krupitza, G. (1999) Mutat. Res. 437, 205-217

2. $\quad$ Simonitsch, I. and Krupitza, G. (1998) Br. J. Cancer 78, 862-870

3. Wu, K., Polack, A., and Dalla-Favera, R. (1999) Science 283, 676-679 


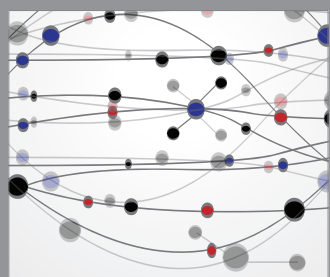

The Scientific World Journal
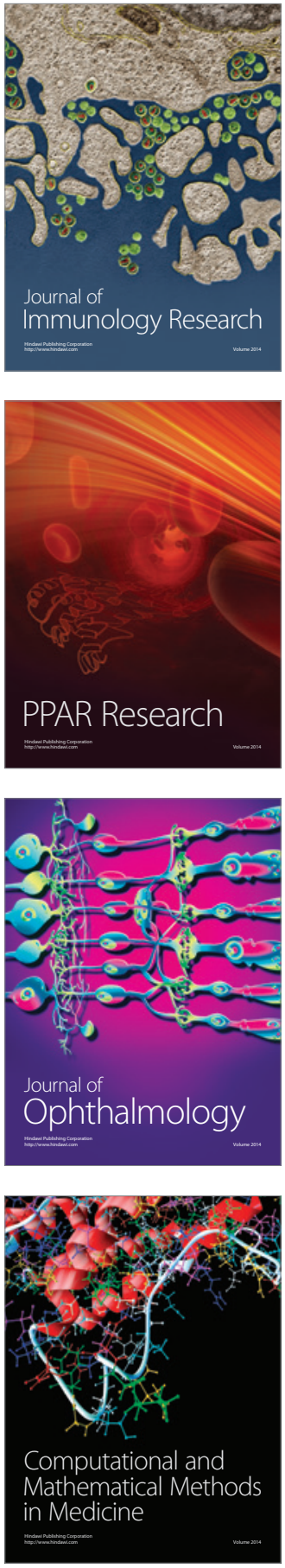

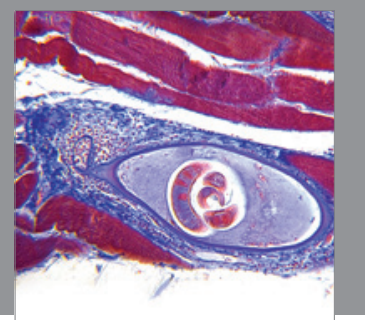

Gastroenterology

Research and Practice
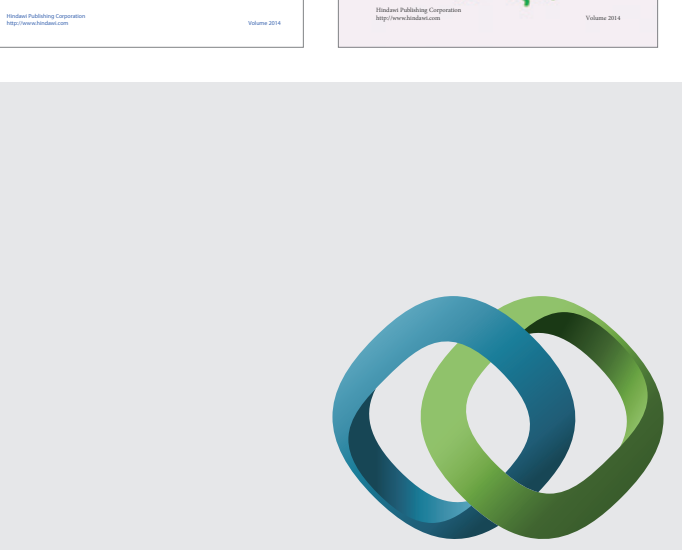

\section{Hindawi}

Submit your manuscripts at

http://www.hindawi.com
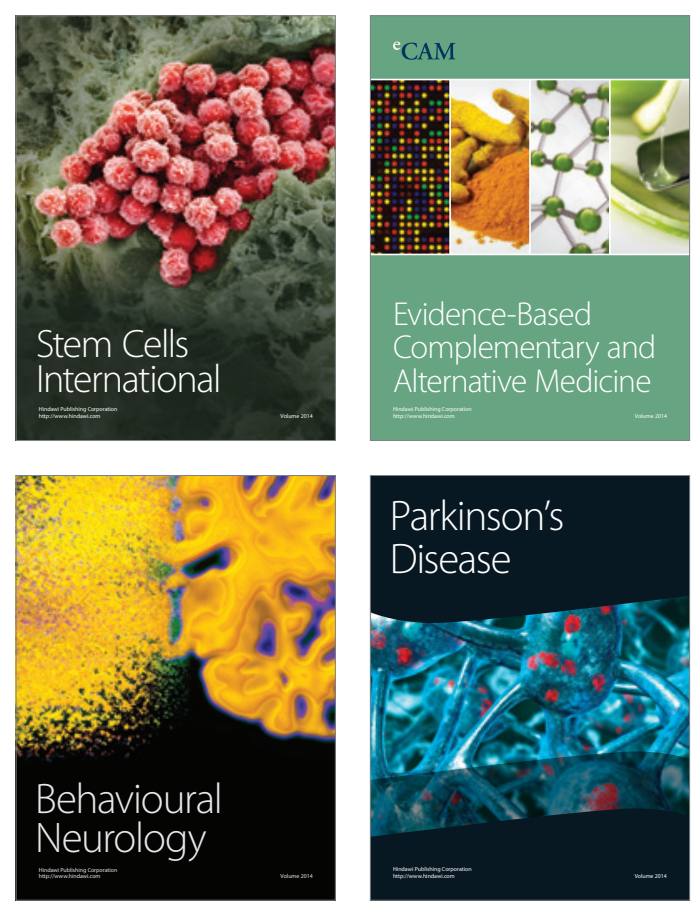

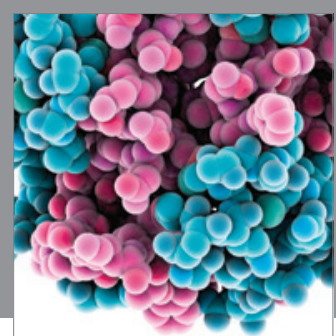

Journal of
Diabetes Research

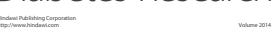

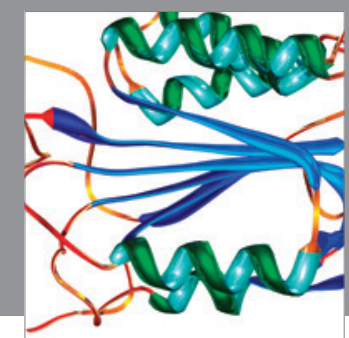

Disease Markers
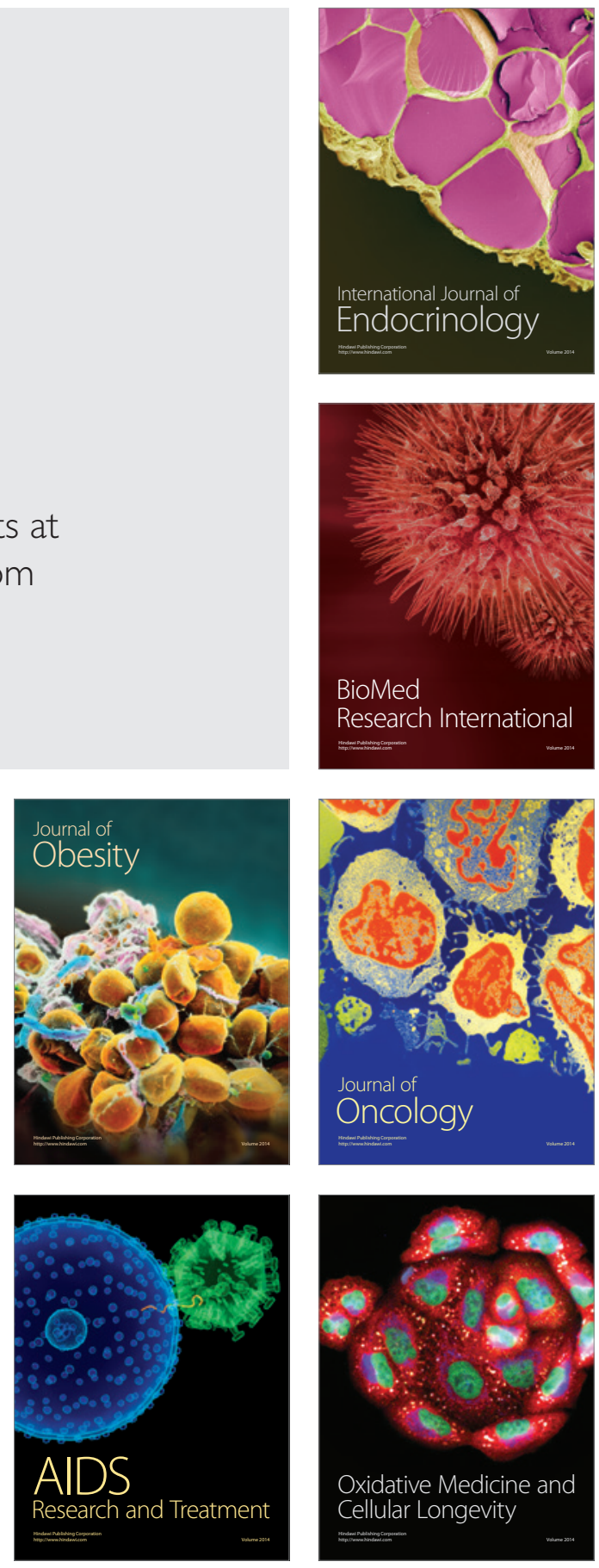